Saleh, Zainab, Avital, Eldad J. and Korakianitis, Theodosios (2020) Effect of in-service burnout on the transonic tip leakage 1 flows over flat tip model. Proceedings of the Institution of Mechanical Engineers, Part A: Journal of Power and Energy, 234(5), pp. 655-669. Copyright (C) 2020 (Sage).

DOI: https://doi.org/10.1177\%2F0957650919877057 


\title{
Effect of In-Service Burnout on the Transonic Tip Leakage Flows over Flat Tip Model
}

\author{
Zainab Saleh ${ }^{1}$, Eldad J. Avital ${ }^{2}$, Theodosios Korakianitis ${ }^{3}$ \\ ${ }^{1}$ Kingston University London, London, UK \\ ${ }^{2}$ Queen Mary University of London, London, UK \\ ${ }^{3}$ St. Louis University, Mo, USA
}

Corresponding Author:

Zainab Saleh, Department of Aircraft and Aerospace Engineering, Kingston University London, Penrhyn Rd, Kingston upon Thames KT1 2EE, UK

Email: z-saleh@kingston.ac.uk

\section{ABSTRACT}

Un-shrouded turbine blades are more common than shrouded ones in gas turbine aeroengines since they reduce the weight and avoid the centrifugal loading caused by the blades' shrouds. Despite these important advantages, the absence of the shroud leads to leakage flows across the tip gap and exposes the blade tip to high thermal load and thermal damages. In addition, the leakage flows can contribute up to $30 \%$ of the aerodynamic loss in a turbine stage. In this study, the effect of in-service burnout is explored using a fundamental flat tip model of a high-pressure gas turbine blade. This investigation is carried out both experimentally in a transonic wind tunnel and computationally using the Reynolds Averaged Navier Stokes approach at high speed conditions. It is found that exposing the tip to the in-service burnout effect changes the leakage flow behaviour significantly when compared to the tip with sharp edges (i.e. the tip at the start of its operational life). Different flow acceleration, flow structure and shockwave pattern and interactions are captured for the round-edge flat tip (i.e. the tip exposed to in-service burnout). The effective tip gap is found to be much larger for the round-edge flat tip allowing more leakage flow into the tip gap which results into higher tip leakage losses in comparison to the sharp-edge tip. Experimental and computational flow visualisations, surface pressure distributions and discharge coefficient are given and analysed for several pressure ratios over the tip gap.

\section{Keywords}

Turbine blade tip, tip leakage, burnout effect, discharge coefficient, wind tunnel tests, RANS. 


\section{NOMENCLATURE}

PR Pressure ratio (ratio of static pressure at the tip gap exit to the stagnation pressure at its inlet)

RANS Reynolds Averaged Navier Stokes

\section{SYMBOLS}

A

$\mathrm{C}_{\mathrm{D}}$

$\mathrm{h}$

M

$\dot{\mathrm{m}}_{\mathrm{act}}$

$\dot{\mathrm{m}}_{\text {isen }}$

$\mathrm{P}_{0}$

$\mathrm{P}_{01}$

$\mathrm{P}_{\mathrm{s}}$

$\mathrm{R}$

$\mathrm{T}_{\mathrm{o}}$

$\mathrm{v}$

$\mathrm{v}_{\mathrm{x}}$

$\gamma$

$\rho$
Area

Discharge Coefficient

Tip gap height

Mach number

Actual mass flow rate

Isentropic mass flow rate

Stagnation pressure

Stagnation pressure at the inlet to the tip gap

Static pressure at the tip surface

Gas Constant

Stagnation Temperature

Velocity

Velocity in $\mathrm{x}$-direction

Adiabatic constant

Mass density

\section{INTRODUCTION}

Gas turbine engines form a significant important part of the aero-propulsion industry and their development and advancement have great impact on the economics of this sector, therefore they are considered as essential research area with high potential. An effective way of enhancing the performance of these engines is through increasing the temperature of the gases entering the high pressure turbine stage. Hence in the modern gas turbine engines, gas temperature at the inlet to turbine stage is pushed to a very high limit. However despite this advantage, this approach will also expose the blades to high temperature and high heat transfer, and requires suitable cooling techniques for the blade material to sustain a sufficiently long operational life $[1,2,3,4]$.

Turbine blade tip is considered as a very complicated region to design within a high pressure turbine stage since it is exposed to a much greater heat load in comparison to the rest of the blade and it is very difficult to be cooled. There have been a lot of research studying the effect of the shrouded and un-shrouded tips on the turbine efficiency, Gao et al. [5] provided a comprehensive comparison between the two. In the case of shrouded blades, a shroud is used to interconnect all the blades and provides a sealing between the tip of the blades and the casing surface. In some industrial applications partial shrouds are 
used to reduce the stresses caused by the full shroud on the blades while still benefiting from some of advantages of shrouded design $[6,7]$.

Despite all the benefits, shroud increases the weight, exposes the blades to mechanical stresses and gives rise to high centrifugal loading therefore there is a high potential to move towards the un-shrouded blades in the aero-engines. In the case of un-shrouded blades, the pressure difference between the blade surfaces gives rise to the development of the so-called leakage flows across the tip gap which starts from the pressure side and ends at the suction side of the blade. These leakages flows expose the tip region to a very high thermal load and damage, hence this region is considered as a critical area to design in the case of the un-shrouded turbine blade. In addition to thermal damages, these leakage flows contribute to one third of the total aerodynamic loss in a turbine stage, therefore any small improvement in reducing these flows will result in a great enhancement in the engine's efficiency $[8,9]$.

There have been a lot of studies on the tip leakage flows to explore the important factors affecting these flows and their development. As the flow reaches the pressure side of the tip, it separates and develops a separation bubble. This acts like a vena-contracta and can accelerate the flow to high speed conditions provided the pressure difference across the tip is sufficient. The development of the high speed flow gives rise to the formation of shockwaves in the tip gap which interact with the tip flow [8, 10]. Moore et al. [11] and Moore and Elward [12] provided a comprehensive study on the development of separation bubble and its vena-contracta effect as well as the formation of the shockwave due to the over expansion of high speed tip flow at the inlet to the tip gap using water table experiments. They showed that as the flow Mach number exceeded 0.8 at the gap exit, tip leakage flow was able to accelerate to supersonic conditions. Chen et al. [8] studied the tip leakage flow at transonic conditions experimentally and computationally using two-dimensional modelling and captured flow fluctuations due to the shockwave formation over the tip surface and its interaction with the leakage flow. It was also discovered that as the tip leakage flows changed from being subsonic to supersonic the length of separation bubble at the inlet significantly decreased.

The chocking behaviour of the tip leakage flows and development of the shockwaves in the tip gap have been pointed out by many studies including research presented by Harvey [13], Green et al., [14] , and Molter et al., [15]. Zhange and He [16] studied the chock nature of the tip leakage flow at transonic conditions and its implications. They discovered that as the tip flow becomes chocked, it sets a limiter to the local tip leakage mass flow rate and results into a decoupling between the mass flow rate of the leakage flow and the blade loading. Therefore, it was concluded that for the chocked tip leakage flow, the blade loading can be increased with a slight or no increase in the tip leakage losses.

The structure of the shockwave developed over the tip surface was studied by Zhang et al. [17]. It was found that most of the tip flow was of supersonic type and had the maximum Mach number of 1.8. In addition the surface heat transfer was predominantly influenced by the structure of the shockwaves formed inside the tip gap. The shockwave 
system started with the formation of an oblique shockwave which reflected at the casing and the tip surface for a few times and ended with the formation of a normal shockwave. On overall the surface heat transfer was smaller at the tip regions with supersonic conditions in comparison to the areas with subsonic conditions.

One of the main factors influencing the tip flow structure and development is the tip geometry. Hence there has been an effort to study different tip geometries including flat tip, suction-side squealer tip, pressure-side squealer tip, cavity tip and winglet tip models and many more $[18,19,20,21,22]$. One of the typical turbine blade tip is known as the squealer tip model, which is effectively a recessed tip and has a thin rim which is extending along either the pressure side or suction side edge or both. Experimental investigations have shown that using squealer tip model reduces the overall heat load when compared to the plain flat tip model. In addition it is found that the squealer rim can reduce the tip leakage flow since it provides sealing effect against this flow [23, 18]. Moreover the location of the rim influences the effectiveness of this tip to a large extent. Study by Kwak et al. [24] shows that the suction side squealer has a better performance in reducing the overall heat transfer over the tip surface in comparison to the pressure side squealer and cavity tip model (i.e. the full squealer tip model). Newton et al. [25] also performed an investigation on different squealer tips with comparison to the flat tip model. It was concluded that the tip flow was dominated by a separation bubble at the inlet to the gap for the flat tip model and the area with separated flows increased by enlarging the size of the tip gap. The heat transfer distributions showed that the suction side squealer model had the best performance since it provided the minimum net heat flux in comparison to the full squealer and the flat tip models. The effect of opening at the leading edge and trailing edge for different squealer tips was explored by Caloni et al. [26]. The opening at the trailing edge was found beneficial in increasing the sealing effectiveness, the leading edge opening allowed more flow entering the tip and the combination of both openings improved the heat transfer distribution.

Another well-known tip geometry is the winglet-squealer model, which has a winglet on the pressure side edge and a squealer rim on the suction side edge. Papa et al. [20] performed an experimental study where this tip geometry was tested and compared to a full squealer model. The heat transfer distribution over the winglet-squealer tip was found to be much lower in comparison to the squealer tip. In addition increasing the tip gap size did not change the overall heat transfer for the winglet-squealer tip whereas for squealer tip the heat transfer was increased for a larger tip gap. More recently Zhong et al., [22] have studied the heat transfer distributions for different winglet-squealer tip models and have explored the implications of different locations of winglet on the flow over the squealer tip.

The development of leakage flow over the blade tip exposes the tip surface to a significantly high thermal load and results in a series of surface damages such as inservice burnout, after being a while in operation [27]. Therefore a more realistic tip model for a blade tip in service is one which its sharp edges have been eroded and turned into round edges due to an exposure to a high heat load. Despite this, there have been very few researches studying the effect of the in-service burnout on the tip leakage flow 
behaviour in high pressure gas turbines, most of which have concentrated on simply looking at the effect of varying the gap height [28]. As far as we are aware there has been only one work done by Ameri and Bunker [29, 30] looking at round-edge tip model of erosion, while focusing on the heat transfer distributions over the tip and the shroud surfaces of a first stage turbine blade in details. However, that research provided no flow visualisation and associated flow analysis was given only for the overall pressure distribution over the tip surface along the pressure side, mean line and suction side of the tip surface.

It is clear from the literature that there is a large gap in knowledge on in-service burnout effect. It is the aim of this study to bridge this gap by studying the tip leakage flows over a flat tip model at the beginning of its operational life i.e. a tip with sharp edges and comparison with a tip geometry exposed to an in-service burnout after a while being in operation i.e. a tip with round edge. This can be done through testing the quasi three dimensional models of both tip geometries. The tip geometries are designed based on the Rains's model of tip leakage flows [31]. This approach and its reasoning are explained next, and in the following section. Flat tip model is the most fundamental model in this field and hence was chosen in this study. Studies of the effect of in-service burnout on more complex tips as of having cavity will be presented in the near future.

This fundamental study focuses on the main aspect of the tip leakage flows which is mainly due to two-dimensional geometry effects $[8,10]$. This is a principal approach embedded in the traditional aerodynamic modelling such as the lifting line theory for studying the wings and the blade element approach to study the blades where the twodimensional geometry effects are first explored and then followed by a three-dimensional study that stiches the two-dimensional flows together by the assumption of high aspect ratio, which is in our case the ratio between the chord length and maximum profile

thickness. Three-dimensional effects will be included in a future publication. The tip geometries in this investigation are tested at the engine operational condition (i.e. transonic conditions) both experimentally and computationally, and the flow visualisation, pressure measurement, different flow contours, and the discharge coefficient, $C_{D}$ (as a measure of loss associated with the tip leakage flows) are obtained.

\section{EXPERIMENTAL PROCEDURE}

The experimental work of this investigation was carried out in the transonic wind tunnel of the high speed section of the White head laboratory, School of Engineering and Materials Science, Queen Mary University of London. This is a closed circuit transonic wind tunnel which has a working section of a cross section area of $127 \mathrm{~mm}$ in width and $135 \mathrm{~mm}$ in height. The flow when passing through the empty working section i.e. without any model, can accelerate up to a maximum Mach number of 1.4.

The tip leakage flows in this study were modelled using the same approach in Chen et al. [8] which was originally proposed by Rains [31]. Rains's model assumed that the pressure gradient in the chordwise direction was much smaller than the pressure variation 
perpendicular to the chord. It proposed that the two components of flow moment in the direction parallel to chord and perpendicular to the chord were decoupled. Rains's model also assumed that the momentum component parallel to chord was approximately constant across the tip gap starting from pressure side and ending at the suction side edge. Using this model the blade tip can be considered as series of planes which are cut perpendicular to the chord of the blade tip as shown in Figure 1.

Yaras et al [32] studied the velocity vector distributions over a turbine blade in a planar cascade in which they found that apart from the areas close to the leading and trailing edges, most of the tip leakage flows cross the tip almost normal to the chord. Hence it was concluded that at any local plane perpendicular to the chord the main variation in the flow momentum is in the direction perpendicular to the blade chord. Typical streamline and main flow features of the leakage flows over turbine blade tip was discussed in Thorpe et al. [33] based on which the leakage flows crosses the tip almost at perpendicular to the tip chord apart from small areas at the leading and trailing edges. Flow streamlines and visualisation of the tip leakage flows presented by different papers showed similar flow pattern $[34,25,19,35]$.

The flow pattern captured in all of these researches shows that the approach used by Chen et al. [8] and the model proposed by Rains [31] are applicable to the leakage flows over the whole tip region except the small areas close to the leading and trailing edges. This confirms the reliability of using two dimensional or quasi three dimensional modelling to study the tip leakage flows. Therefore the results obtained from this study should be applicable to the leakage flows over the blade tip regions where flow is perpendicular to the chord except for the areas close to the leading edge and trailing edge.

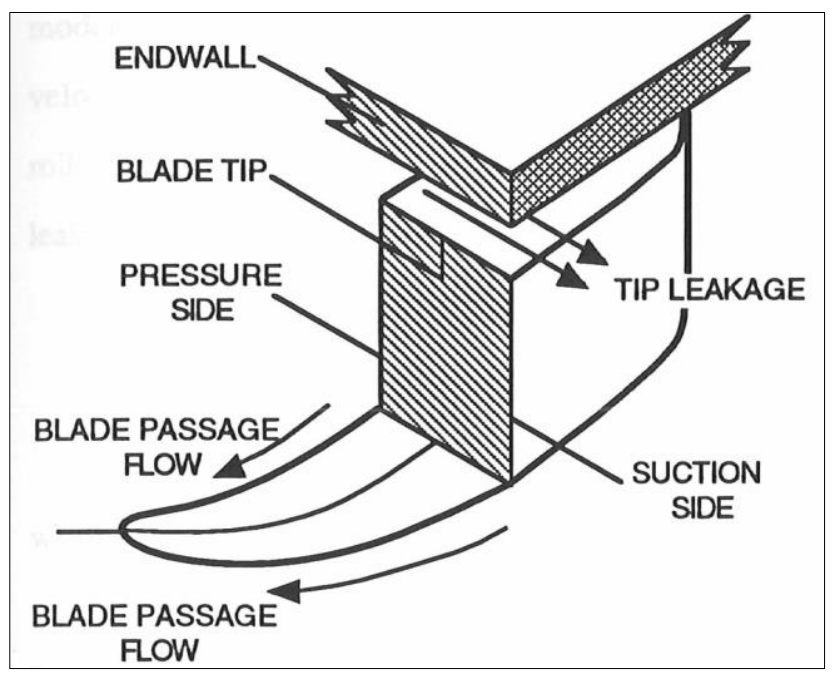

Figure 1: Simple modelling of leakage flow by considering a plane perpendicualr to chord direction (introduced by Rains) [36]. 


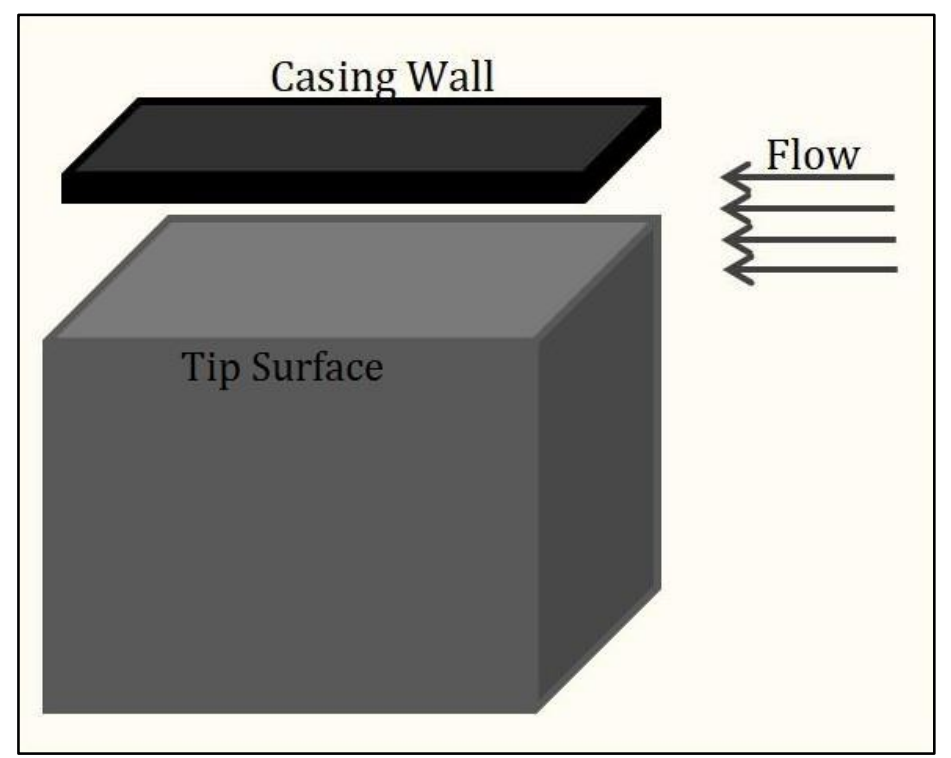

Figure 2a: The sharp-edge flat tip model.

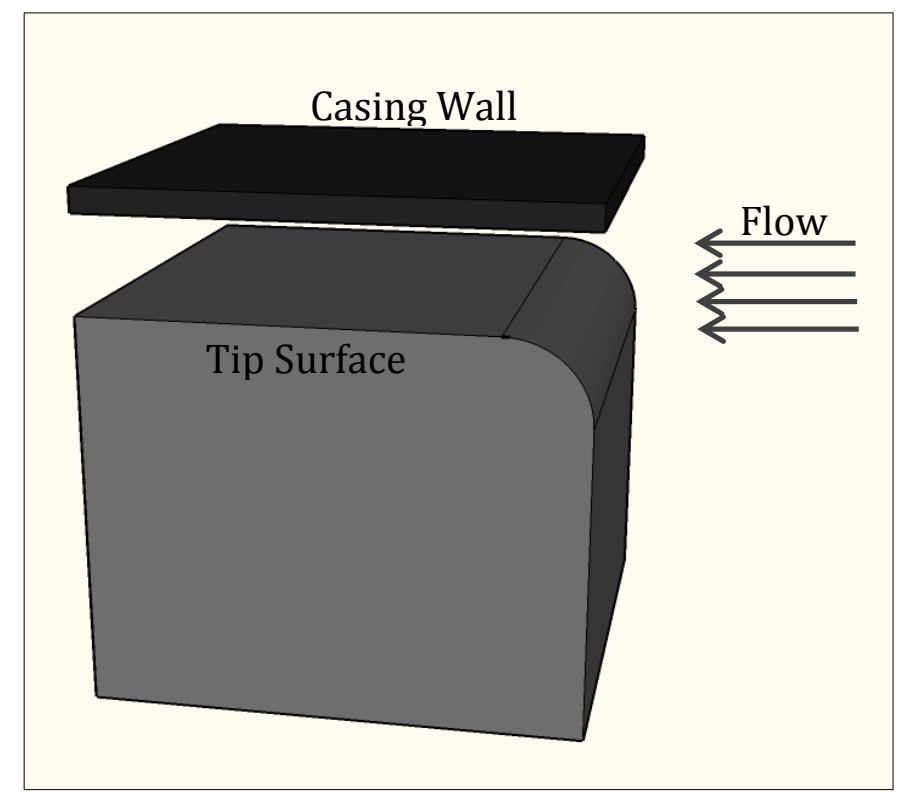

Figure 2b: The round-edge flat tip model.

Figures $2 \mathrm{a}$ and $2 \mathrm{~b}$ show the experimental models tested in this investigation. The top surfaces of the models represent the tip surfaces and the top wall of the working section represents the casing surface. The axial length of each tip is $100 \mathrm{~mm}$ and the tip gap height for both models is $20 \mathrm{~mm}$ which is about 10 times greater than the actual tip gap height in the real engine. This scale was chosen since operating the transonic wind tunnel at narrow tip gap was extremely difficult and almost not possible. 
The ratio of the tip gap height to the streamwise length of the gap is 5 which corresponds to the middle section of the tip surface of the high pressure turbine blade in the real engine where the thickness is maximum. This is the region on the tip which is furthest from the leading and trailing edges, and the leakage flow crosses the tip gap at a direction almost perpendicular to the chord line. Changing the gap mildly was found not to fundamentally alter the flow regime. For example slightly increasing the gap was found to mildly reduce the flow speed in the gap and in the transonic case to mildly lengthen the system of the oblique shockwaves (to be discussed later). A comprehensive study of the effect of varying the ratio of the gap height to the streamwise length is left for future research. The quasi-three dimensional principle used in the experimental work and the two-dimensional principle used in the computational work which were based on the Rains's model, are applicable to provide reliable fundamental results. In addition the radius of the round edge in the case of the round-edge tip model is $10 \mathrm{~mm}$ and the ratio of this radius to the height of the tip gap is 0.5 . This represents a simple model of a roundedge tip, a tip being in service and exposed to high heat load.

Flow visualisation is a very effective technique to establish more insight into the flow field and flow behaviour. In this investigation Schlieren flow visualisation was used to capture the important flow features. This is an optical technique which visualises the refractive index in the testing section. In the case of the tip leakage flows of this investigation the refractive index changed as a result of a change in the density since the flows were of compressible type. Figure 3 shows the setup of the z-type Schlieren flow visualisation which was used in this study, this figure is based on the diagram by Settles [37]. As it can be observed the set up includes two parabolic mirrors which are oppositely tilted, an extended light source, a camera and a knife edge. The light rays from the light source (which is located at the focal point of the first mirror) reach and reflect at the first mirror. This mirror is then rotated to direct the rays into the test section. The light rays travel to the second mirror and reflect. The reflected rays carry the information of the flow in the working section which can be captured by a camera. The most focused image of the flow is formed at the focal point of the second mirror. Using a knife edge at this point can help with adjusting the sensitivity of the Schlieren set up via blocking some of the reflected light rays. The more rays blocked by the knife edge, the more sensitive the set up becomes, hence more flow structure and disturbance can be captured by the set up [37].

In addition the static pressure distribution was measured at the tip surface of the models using $2 \mathrm{~mm}$ pressure tappings and a suitable scannivalve. These formed the quantitative experimental results in this study. All the experimental results of the two tip models are presented in the Results section. 


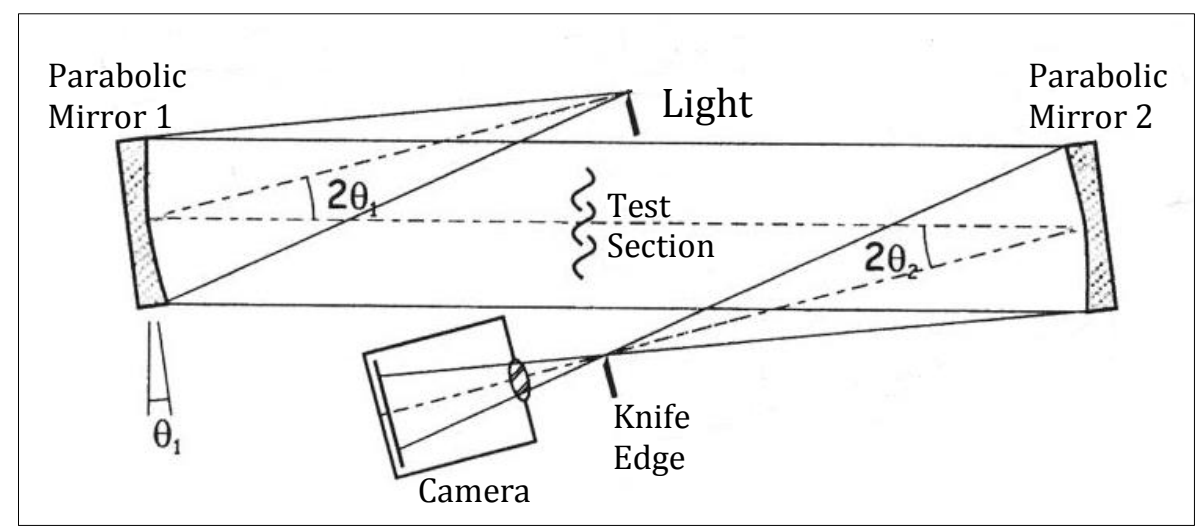

Figure 3: Z-type Schlieren flow visualisation set up in this investigation. [37]

\section{COMPUTATIONAL PROCEDURE}

The flow domains for both sharp-edge flat tip and round-edge flat tip models were meshed and solved using the ANSYS commercial package. Structured mesh (i.e. quadrilateral mesh cells) was used for the sharp-edge flat tip model whereas the flow field of round-edge flat tip was meshed using hybrid mesh, combination of structured and unstructured mesh cells (i.e. using both triangular and quadrilateral mesh cells). The computational domains for both tip models are included in Figures 4, where for clarity only one fifth of the computational grid lines are plotted. The tip leakage flows for both sharp-edge and round-edge tip geometries were computed using the Reynolds Averaged Navier-stokes (RANS) equations approach and compressible Spalart Allmaras model was selected as the turbulent model for both tip models.

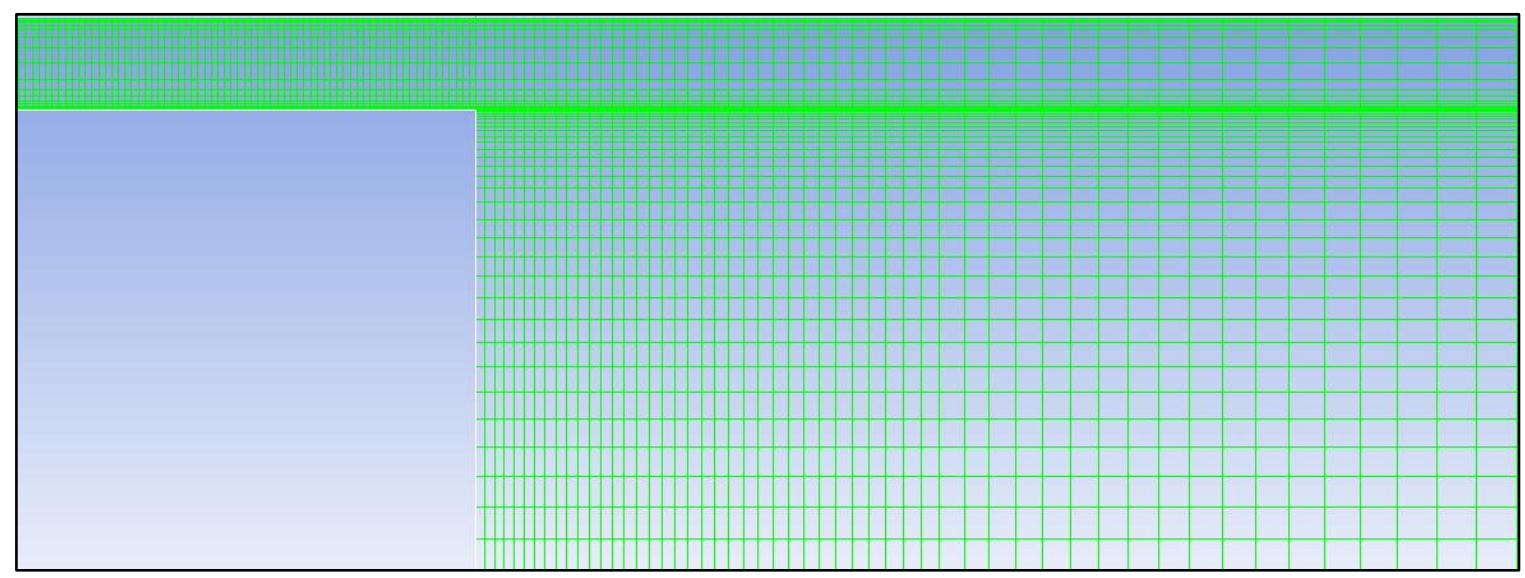

(a) 


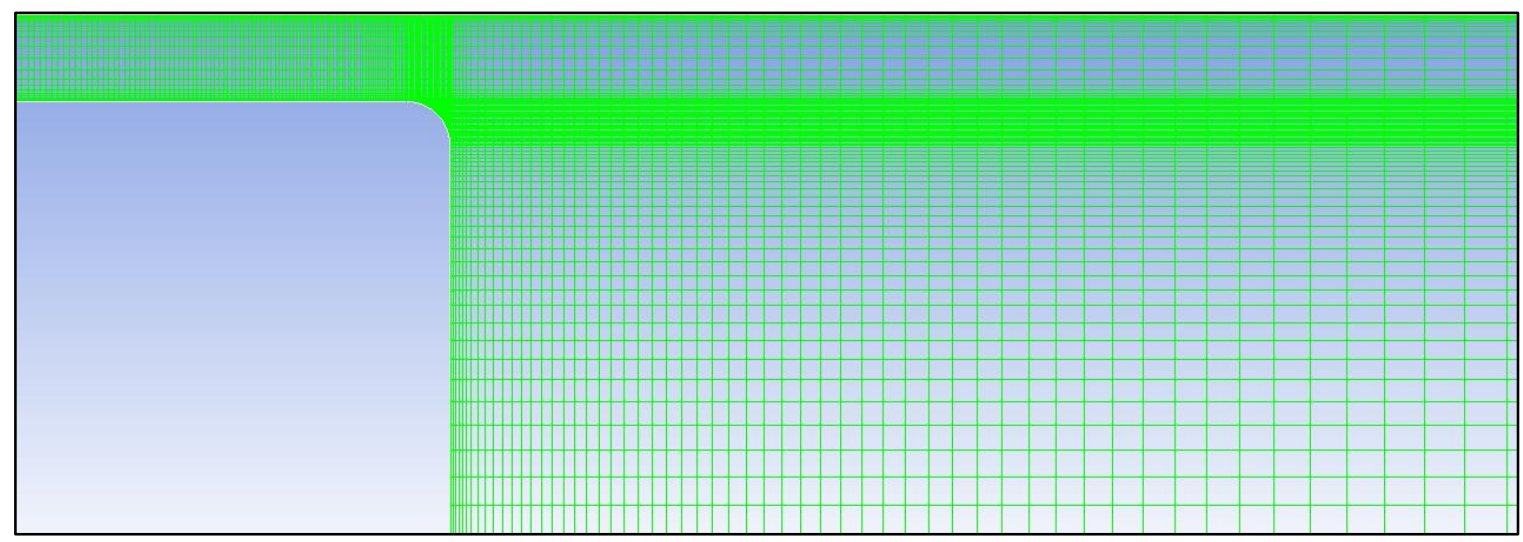

(b)

Figure 4: The computational domain for (a) the sharp-edge flat, (b) round-edge flat tip models, where for clarity only one fifth of the computational grid lines are plotted.

The pressure inlet and pressure outlet boundary conditions were used at the inlet to the tip gap and its exit. Adiabatic wall with no slip condition was chosen for all the solid boundaries within the computational domain. The tip leakage flows for both tip geometries were solved using FLUENT within ANSYS where finite volume method and collocated grid approach were applied. Since the tip flows were of compressible type, the density-based solver was employed, and in order to enhance the convergence rate and stability, implicit solution method was used as the time-averaged flow solution was sought for the RANS. In addition second order upwind scheme was used for the convection terms and second order central scheme was applied for the diffusion terms. The first grid point above each solid boundary was at a distance with $\mathrm{y}+$ value of about 30 and hence at the log region of the turbulent boundary layer. Therefore enhanced wall models were used in the RANS solution for both tip models.

It was important to use very fine mesh cells in the flow area where very large gradient were expected. These included the gap between the blade tip and the casing wall where flow features such separation, shockwave and etc were anticipated. Hence there were 100 nodes used within the tip gap region (in the vertical direction) for both tip geometries. The distance between the nodes was adjusted so that more nodes were used close to the tip surface and the casing wall. In addition mesh independency study was established to ensure that mesh resolution has reached the sufficient level beyond which increasing the mesh refinement does not influence the computational data. This was established via increasing the grid density at the domain areas with large gradients and monitoring the flow data at different mesh resolutions. The flow data which were compared at different grid resolutions included both the direct data from the simulations such as the tip surface static pressure and those which were calculated using the flow data such as the discharge coefficient (as a measure of loss). The grid resolution beyond which increasing its refinement and cells did not change the flow results (or only changed it by a negligible value), was selected as the sufficient resolution providing grid independent results. In the case of this study the grid with $1.1 \times 10^{5}$ cells was found as a sufficient mesh resolution providing grid independent results. In addition in each case, simulation continued running 
to the point where the residual plots flattened at the sufficient level and running further iterations did not change the results.

\section{RESULTS}

This section includes both experimental and computational results of both sharp-edge flat tip and round-edge flat tip models. The flow Reynolds number based on the tip gap height and the flow conditions at the exit, was about $2.5 \times 10^{5}$, which is about five to ten times greater than that found in the typical engine conditions. However the computational works for tip flows at different Reynolds numbers showed that the tip flow behaviour and the shockwave structure within the tip gap were not affected considerably by this much difference in the flow Reynolds numbers. In addition tip leakage flows were tested at different pressure ratios in a range of 0.85 to 0.58 which covered different flow conditions of both subsonic and transonic for comparison. The leakage flows over high pressure turbine blade tips are mostly transonic, hence the transonic pressure ratios tested in this investigation are relevant to the typical operating conditions of a high pressure turbine in an engine.

Figures 5 illustrate the experimental Schlieren flow visualisation for the flat tip model with sharp edge at three different flow conditions with PR (i.e. the ratio of the static pressure at the exit to the stagnation pressure at the inlet of the tip gap) of $0.58,0.60$, and 0.65. As it was explained in the "Experimental Procedure" Schlieren flow visualisation is an optical technique which visualises the refractive index gradient which can be due to the density changed or temperature change. The focus of this study is the aerodynamic behaviour of the tip flows and the refractive index gradient of the flows tested in the wind tunnel was due to the density change since the flows were of compressible type with high speed conditions. Hence one parameter that can be defined to form the base on which the Schlieren results in this investigation are developed, is the density gradient. In Figures 5 the compressible flow features including acceleration through an expansion fan, oblique and normal shockwaves as well as other flow structures such as separation bubble are outlined by black pattern within a bright background. This is since these flow patterns form regions of flow with high density gradient in comparison to rest of the flow field. The effect of the PR on the development of these features in the Schlieren results are explained in the following.

As the flow reaches the leading edge of sharp-edge flat tip model, it turns to adjust itself around the tip geometry and accelerates. This acceleration is similar to the acceleration of the flow around the leading edge of an aerofoil. However since the edge of this tip is sharp, flow separates on its arrival and forms a separation bubble. This separation bubble acts like a vena contracta and can accelerate the tip flow to transonic condition provided the pressure difference across the tip is sufficient. 


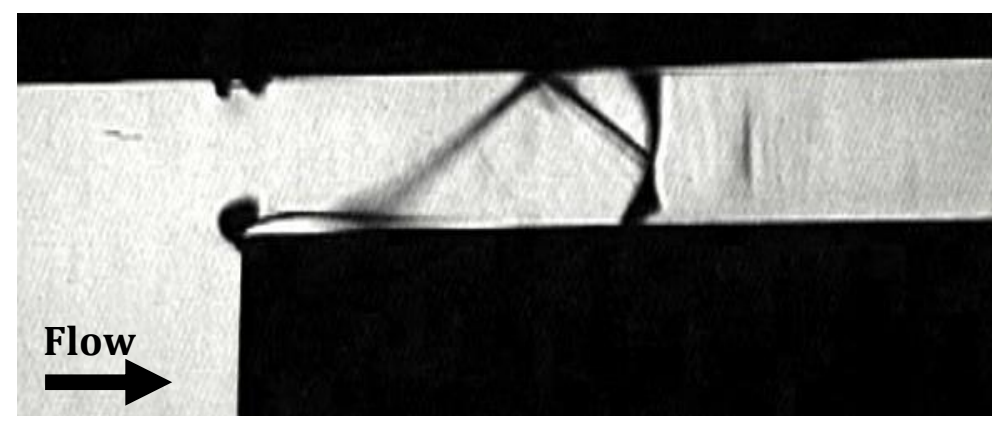

(a)

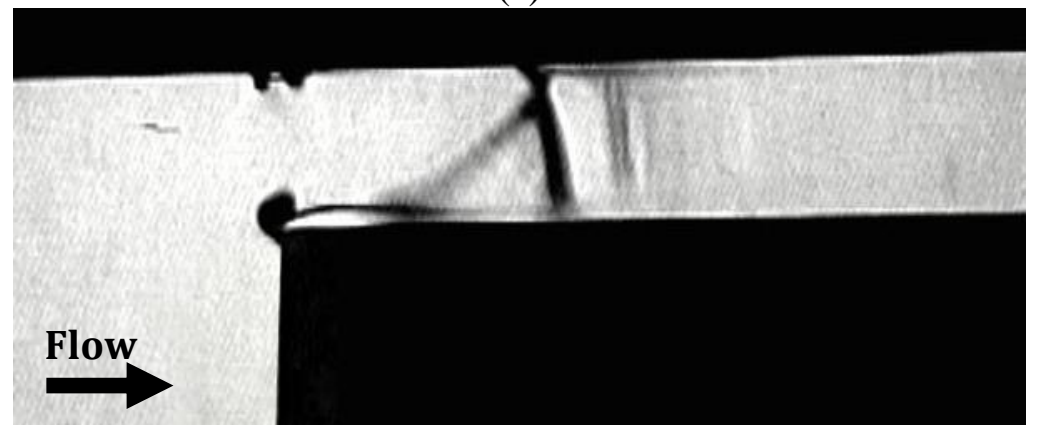

(b)

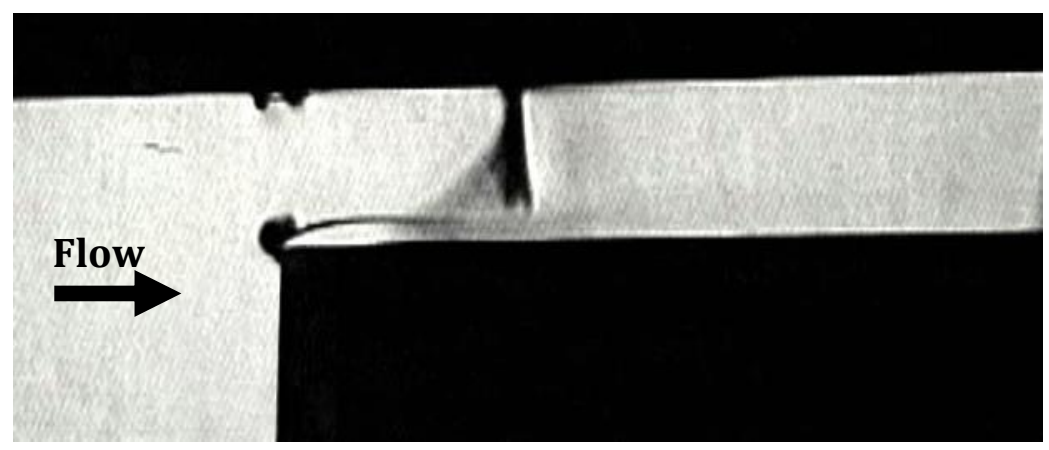

(c)

Figure 5: Experimental Schlieren flow visualisation over sharp-edge flat tip model at different PR of a) 0.58, b) 0.60 , c) 0.65 .

In all cases presented above the pressure difference across the tip has accelerated the leakage flow to transonic Mach numbers. In addition as the pressure ratio PR decreases from 0.65 to 0.58 , the pressure difference across the tip and hence the acceleration of the tip flow which occurs through an expansion fan at the leading edge increases, the size of the of the expansion fan becomes larger for smaller PR. Larger flow acceleration at the inlet leads to more coherent shockwave development within the tip gap. The shockwave formation starts at the aft portion of the separation bubble where numbers of compression waves form and collapse to form an oblique shockwave. As illustrated by Figures 5, for PR of 0.58 this oblique shockwave reflects as another oblique shockwave at the casing wall and the pattern ends with a normal shockwave. In the case of $P R=0.60$ the pattern includes one oblique shockwave and one normal shockwave and in the case of $\mathrm{PR}=0.65$ there is only one normal shockwave. 
Another flow feature which is clearly captured in the Schlieren results is the separation bubble, as the PR decreases from 0.65 to 0.58 the size of the separation bubble decreases and this is due to an increase in the acceleration of the tip flow which suppresses the separation bubble and decreases its size. The effective tip gap for this tip is defined as the minimum distance between the casing wall and the separation bubble, hence as the PR decreases the effective tip gap increases as a result of suppressing the separation bubble. Schlieren technique provides qualitative results and is developed based on density gradient as the main parameter in this investigation. It can be observed as the PR decreases there is larger flow area with distinguishable and high density gradient.

The experimental surface static pressure distributions over the tip surface of the sharpedge flat tip provide quantitative results and are included in Figure 6 for the three cases presented in Figures 5. The streamwise distance of $X=0 \mathrm{~mm}$ in this figure, indicates the leading edge of the sharp-edge model i.e. the tip pressure side edge and $X=100 \mathrm{~mm}$ is the tip suction side edge.

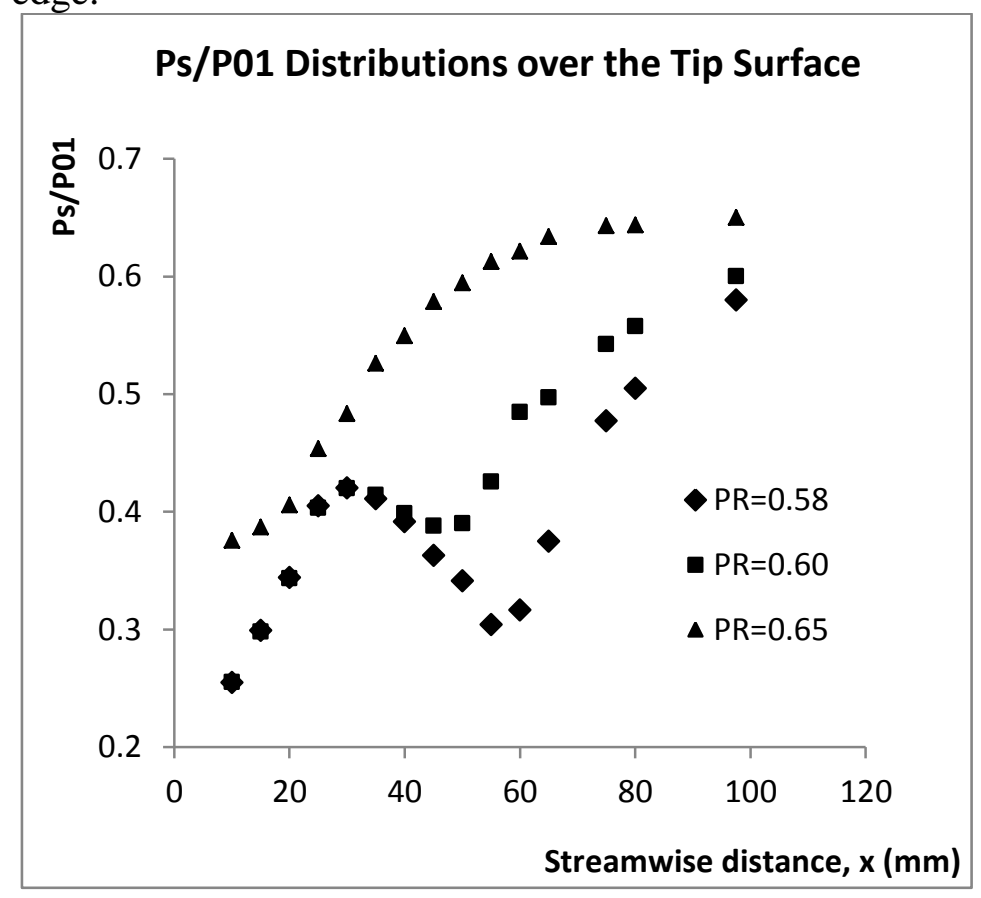

Figure 6: Experimental surface static pressure distributions of sharp edge flat tip model.

As evident in Figure 6, the pressure distributions dictate the patterns captured by the Schlieren flow visualisations shown in Figures 5. For PR of 0.60 and 0.58 , each distribution includes an interruption which is due to the normal shockwave present in each case. The interruption in the case of the $\mathrm{PR}=0.58$ is stronger since in this case the pressure difference across the tip is higher and hence the normal shockwave is much stronger in comparison to the case with $\mathrm{PR}=0.60$. In addition for $\mathrm{PR}=0.65$, the pressure distribution does not include any indication of the normal shockwave, this is since the normal shockwave is much weaker in this case and it is formed over the separation bubble. 


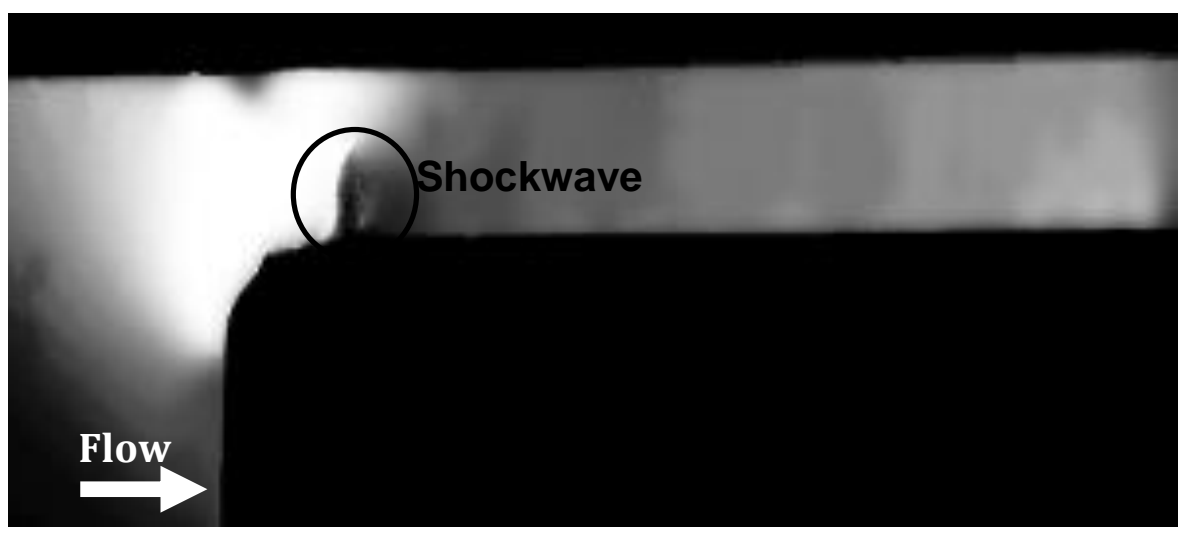

(a)

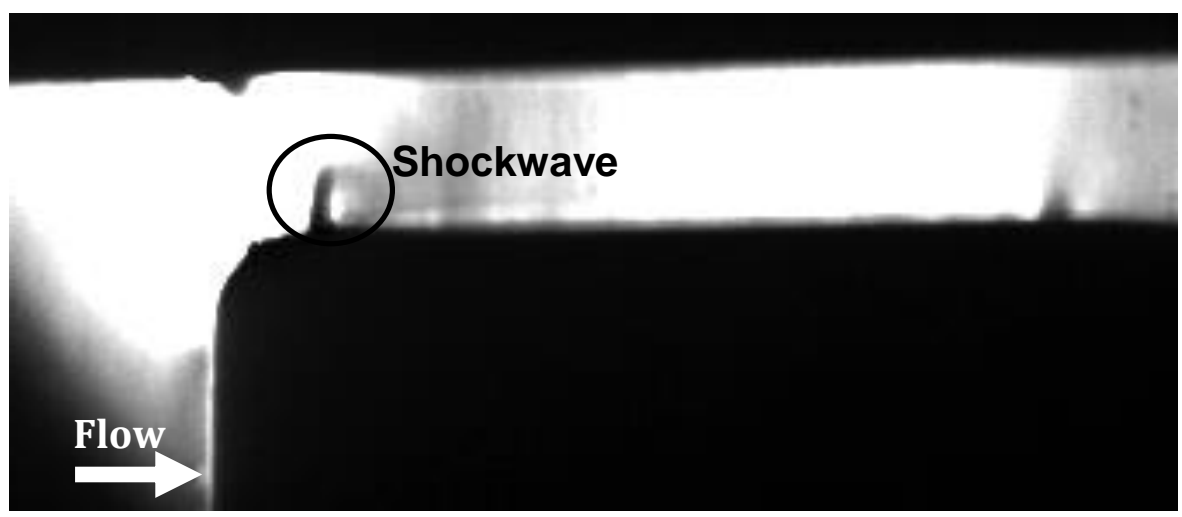

(b)

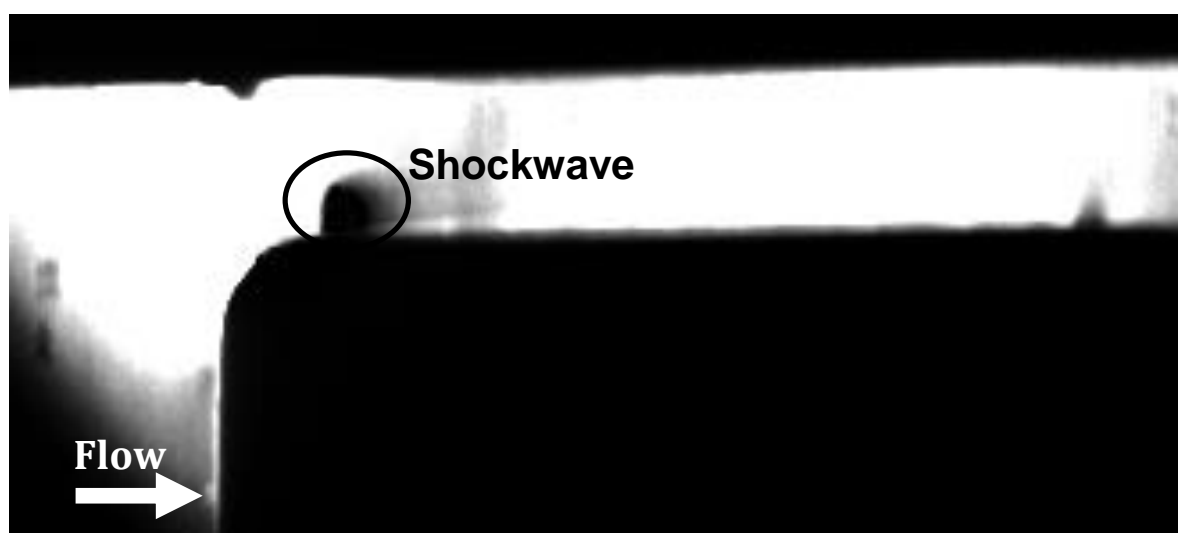

(c)

Figure 7: Experimental Schlieren flow visualisation over round-edge flat tip model at different PR of a) 0.58, b) 0.60 , c) 0.65 .

Schlieren flow visualisation for the round-edge flat tip model (which represents the model exposed to the burnout effect) at pressure ratios of $0.58,0.60$, and 0.65 are included in Figures 7. Similar to the Figures 5, here the Schlieren results are developed based on density gradient being the main parameter, and the black flow patterns in light background represent the flow features with high density gradient i.e. with compressibility effects. For this tip, the flow behaves in a very different manner 
compared to the sharp-edge model. The first difference that is noticeable in these figures is the absence of the separation bubble which was present for the sharp-edge flat tip and dominated its leakage flows. This is due to the leading edge of this model being round which allows the flow to turn, accelerate and adjust itself smoothly without causing any separation. The acceleration of the tip flow for the flow conditions presented in Figures 7 is such that leakage flows reach transonic conditions and include high speed flow features such as shockwave. The development of the shockwave occurs at the point where flow passes over the round leading edge of this tip, it has to change its direction and align itself parallel to the rest of tip surface. Since the flow is of high speed compressible regime the change of direction gives rise to the production of a number of compression waves that collapse and form a shockwave. The shockwaves in these figures are less visible compared to those shown in Figures 5 thus the flow resistance is reduced for the roundedge tip.

One interesting and remarkable flow feature which can be observed for the flow over the round-edge flat tip model is the developed shockwave over this tip. In this case the formed shockwave does not reach the casing (upper) surface unlike the one in the case of the sharp-edge flat tip model. In addition as the pressure ratio, PR decreases from 0.65 to 0.58 the pressure difference across the tip and hence the tip flow acceleration increases and this leads to a taller shockwave meaning the acceleration in the traverse direction increases and hence the area with high density gradient increases in the traverse direction.

The experimental surface static pressure distributions of round-edge flat tip model for these flow conditions are included in Figure 8 which dictates the patterns observed in the Schlieren results. The streamwise position of $X=0 \mathrm{~mm}$ in Figure 8 , indicates the leading edge of the round-edge model i.e. the tip pressure side edge and $X=100 \mathrm{~mm}$ is the tip suction side edge. The distributions start with a very steep and sudden gradient in the static pressure, this occurs in the location where the normal shockwave is developed for this tip model. As the pressure ratio increases from the 0.58 to 0.65 the interruption due to the normal shockwave becomes weaker. This is because as the pressure ratio increases the pressure difference across the tip and the acceleration of the tip flow decrease, hence the shockwave becomes weaker.

The Mach number contours of both models at $\mathrm{PR}=0.58$ are shown in Figures 9. Comparing these contours with the experimental Schlieren results in Figures 5a and 7a, shows there is a good qualitative agreement between the experimental and computational results of both tip geometries. In addition comparing the position of the shockwave in the experimental and computational results, it can be seen that for the round-edge model the shockwave is developed in the same position in both experimental and computational results. For the sharp-edge model the shockwave is developed earlier in the computational case compared to the experimental one, i.e. the shockwave position is shifted by about $5 \mathrm{~mm}$ towards the pressure-side edge. This is discussed in more details later in this section.

For the round-edge tip, the Mach number contours show that the acceleration of the tip flow changes significantly in the traverse direction (i.e. from the tip surface to the casing 
surface in the vertical direction). This variation is such that the flow close to the tip surface reaches transonic Mach numbers and gives rise to the shockwave production while the flow near the casing wall at the same streamwise location is subsonic.

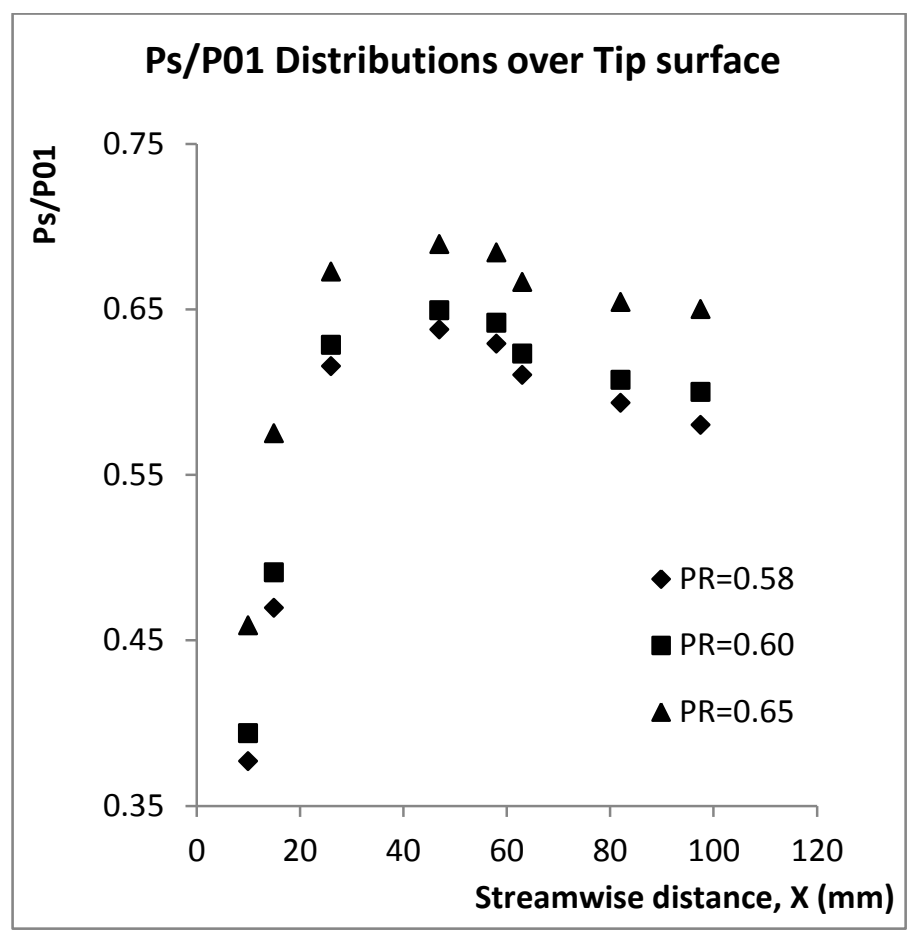

Figure 8: Experimental surface static pressure distributions of round-edge flat tip model.

The computational flow velocity streamlines shown in Figures 10 present clear captures of features such as flow separation and flow smoothness for both tip geometries at $\mathrm{PR}=0.58$. The tip leakage flow is completely attached for the round-edge model and hence effective tip gap in this case is the same as the geometrical tip gap i.e. the minimum distance between the casing surface and the tip surface. Whereas in the case of the sharp-edge geometry, there are two separations over the tip surface. The first separation occurs on the flow arrival due to the pressure side edge being sharp and results into a large separation bubble at the inlet to the tip gap and the second separation is much smaller and occurs further downstream due to the interaction of the normal shockwave with the boundary layer. The effective tip gap for this tip is defined as the minimum distance between the separation bubble at the inlet and the casing surface. The comparison between the effective tip gaps of the two tip geometries shows that the effective tip gap is much larger in the case of the round-edge flat tip model than for the sharp-edge tip. Therefore the tip leakage flow and its associated losses are expected to be greater for the round-edge tip model compared to the sharp-edge one. 
$\Sigma \mathscr{C}_{0}$

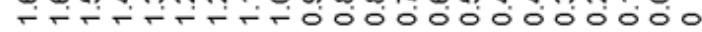
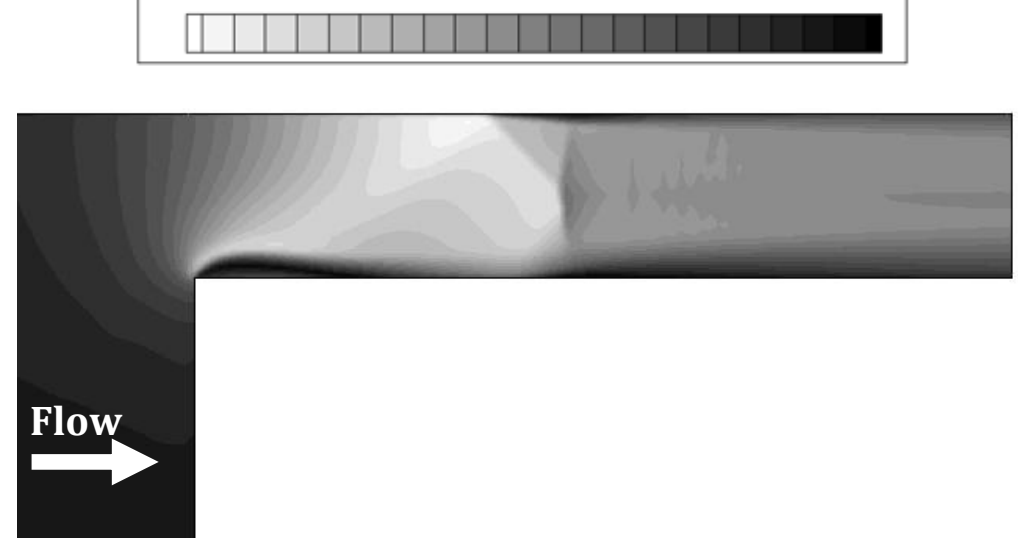

Figure 9.a: The computational Mach number contours of the sharp-edge flat tip model with $\mathrm{PR}=0.58$.

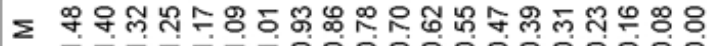
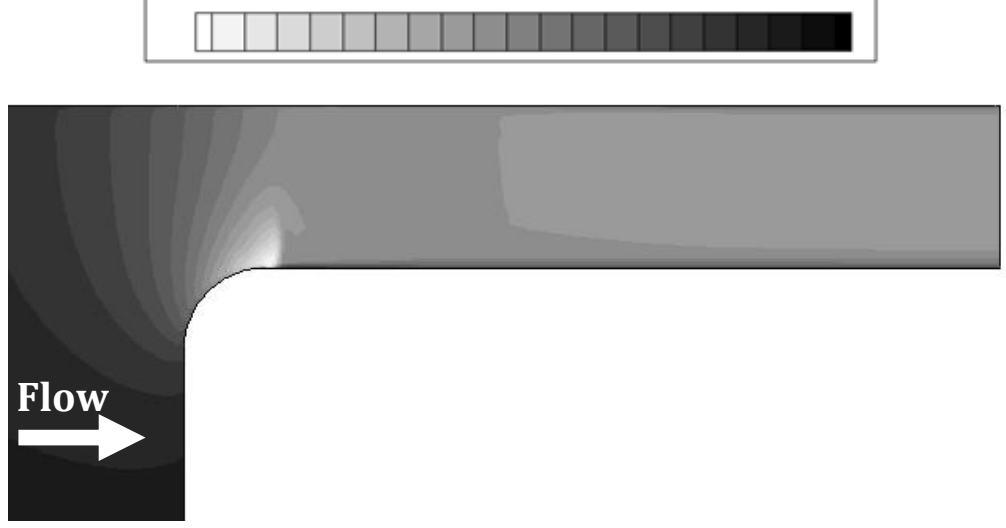

Figure 9.b:The computational Mach number contours of the round-edge flat tip model with $\mathrm{PR}=0.58$.

The experimental and computational static pressure distributions over the tip surface for both tip geometries at $\mathrm{PR}=0.58$ are shown in Figure 11. This is the pressure ratio which represents a well-established transonic tip leakage flows with well-established shockwave system and largest flow acceleration and Mach number for both tip geometries. For the sharp-edge flat tip, the leakage flow for this PR consists of two oblique shockwaves and one strong normal shockwave. It is the only case where at least one shockwave reaches the attached flow over the tip surface and interacts with it. For the round-edge tip, $\mathrm{PR}=0.58$ also has the strongest shockwave compared to the other two cases. In this figure the leading edge of each model is indicated by $\mathrm{X}=0 \mathrm{~mm}$ which represents the tip pressure side edge and $X=100 \mathrm{~mm}$ belongs to the suction side edge of each tip. As it can be observed there is a significant difference between the distributions of pressure over the round-edge flat tip compared to the sharp-edge model. 
For the sharp-edge model, the static pressure distribution is almost flattened over a region at the inlet to the tip gap. This is due to the flow being separated over this area, as observed in the earlier figures, flow separates on its arrival at the tip and forms a separation bubble such pattern also exists in higher PRs. But further downstream the distribution includes a sharp interruption which is due to the development of the shockwave in this region and its interaction with the boundary layer reflecting the strong transonic nature of the flow in this case which is much stronger compared to the higher PRs. The pressure then increases smoothly downstream of shockwave and becomes almost constant near suction side edge.

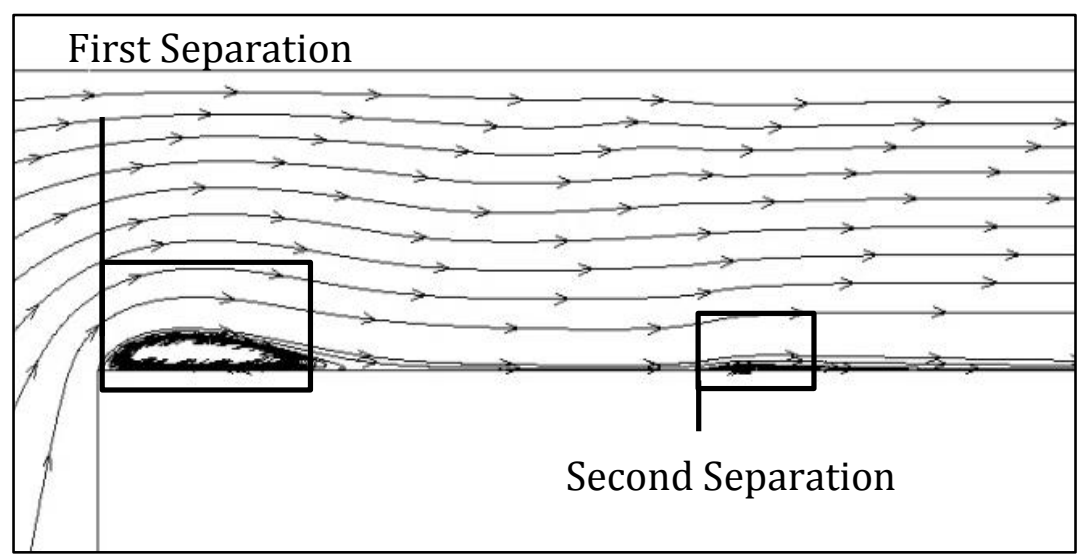

Figure 10a : The flow velocity streamlines over sharp-edge flat tip model, at $\mathrm{PR}=0.58$

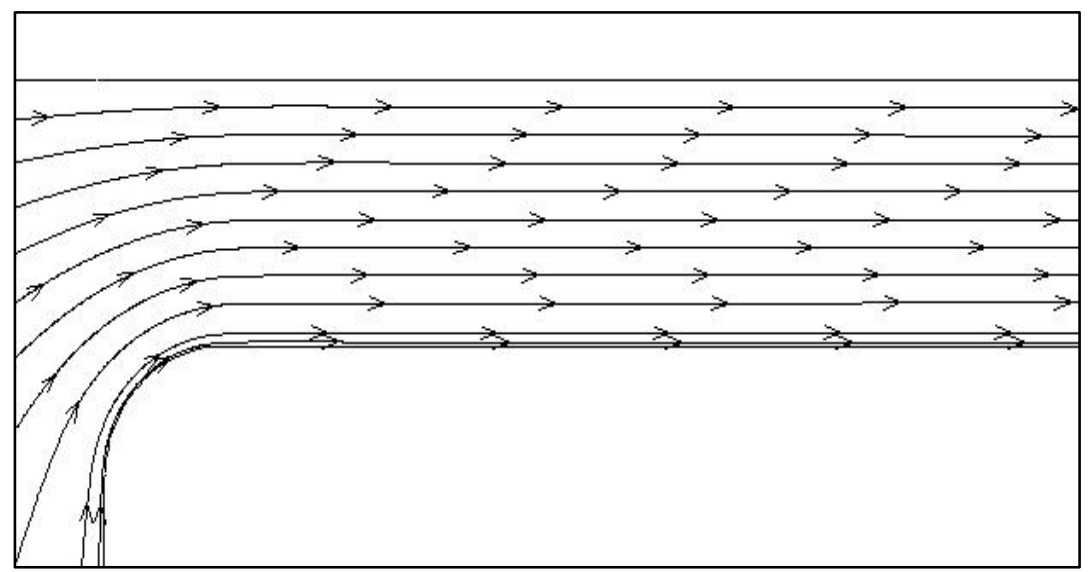

Figure 10b: The flow velocity streamlines over round-edge flat tip model, at PR=0.58.

There is a remarkably good agreement between the experimental and computational pressure distributions for the sharp-edge flat tip. It can be seen that qualitatively the simulations have predicted the same trend as the experimental distribution, and quantitatively there is a very strong agreement between the two. It can be also observed that the computational distribution has mildly under-predicted the length of the separation bubble at the inlet to the tip gap and this has caused the streamwise position of the interruption due to the normal shockwave, to be shifted by a small distance towards the pressure side edge of the tip. This is an expected result since the simulations were carried 
out assuming fully turbulent flow and the shape of the separation bubble is affected by the mixing within the bubble. In the experimental case the shear layer is more likely to be laminar at the beginning and then becomes turbulent hence the mixing within the separation will be slightly different and the separation reattachment will be delayed. Therefore flow reattaches further downstream increasing the length of the separation and resulting in shifting the experimental pressure distribution further downstream.

This type of agreement and similarity are always expected when comparing the experimental and computational data of this kind. Similar comparison was obtained by Fordham [36], where the separation bubble length over flat tip model (at high speed conditions) was under-predicted by the computational work in comparison to the experimental results and this resulted in shifting the computational pressure distribution towards the pressure side edge, similar to the results presented here. Wheeler et al. [38] also observed similar comparison and agreement in their study for the flat tip model at high speed conditions, where the length of the separation at the inlet to the tip gap was under predicted by their simulation. Hence it can be seen that this agreement is similar to those obtained by other studies. Also, the qualitative trend and quantitative values of the maximum and minimum peaks of the experimental and computational distributions have very strong agreement. In addition the computational testing was mesh independent hence it can be concluded that the simulations were reliable and provided sufficient solidity.

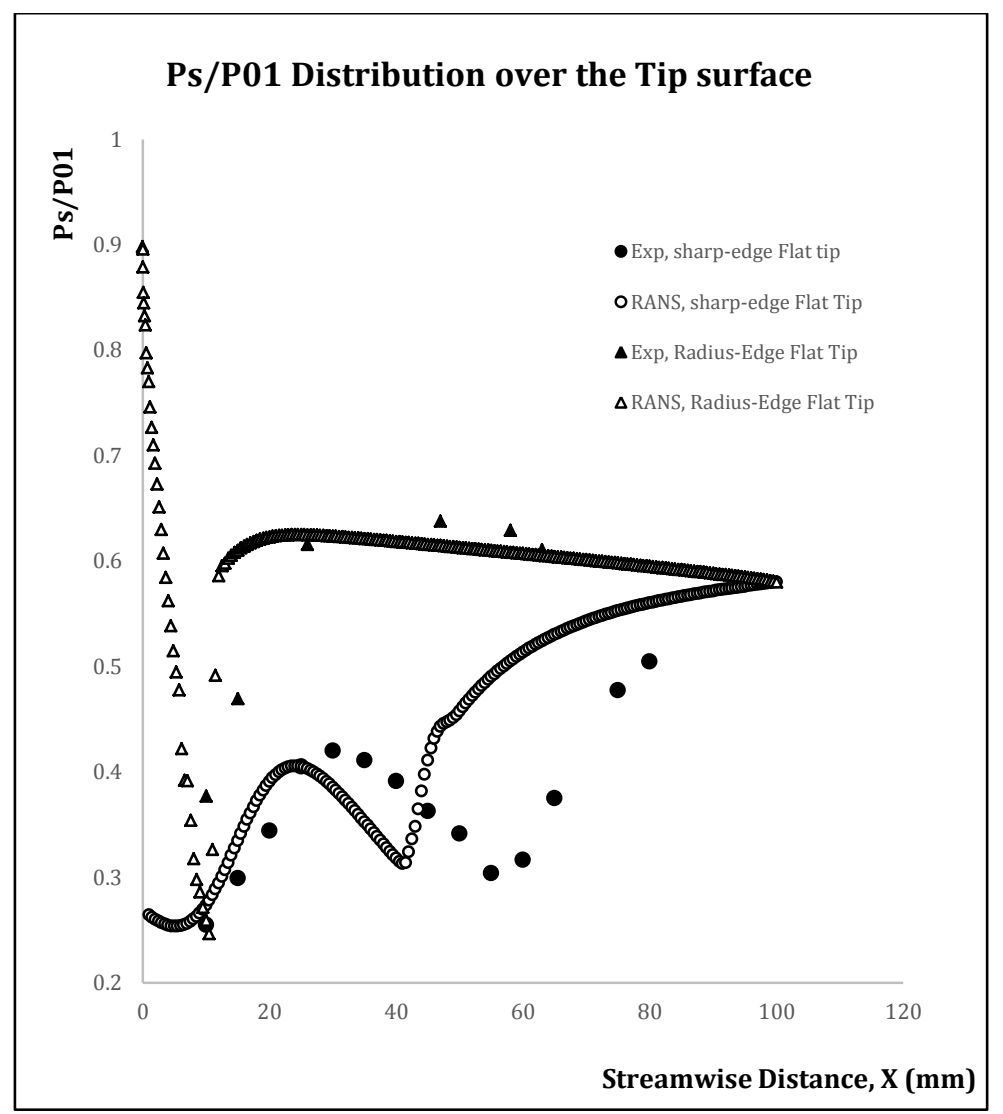

Figure 11: Static pressure distributions over Tip surface at $P R=0.58$ (i.e. the case with well-established transonic flows, shockwave system, and highest flow Mach number). 
In the case of the round-edge model, there is a very sharp decrease in the tip surface static pressure distribution at the inlet to the tip gap. This is due to the development of the shockwave at that region as observed in the flow visualisation results. The flow acceleration is the highest in the presented case and hence the shockwave is the strongest and has the most pronounced interruption. Further downstream the pressure variation becomes very small and then flattens close to the tip gap exit. The agreement between the experimental and computational distributions for the round-edge tip model, are even better than for the sharp-edge one and at some regions the data are almost identical. This is because the flow over this tip does not have the complications due to the separation bubble which is present in the case of the sharp-edge model. The strong quantitative and qualitative agreement between the experimental and computational studies for the roundedge flat tip model demonstrates again the viability of the presented results.

\section{LOSS ESTIMATION, DISCHARGE COEFFICIENT}

The losses associated with the tip leakage flows contribute to about one third of the total losses in the high pressure turbine stage [9]. In addition these losses are proportional to the leakage flow mass flow rate. Therefore any small improvement in reducing these flows can have a significant impact on enhancing the turbine and engine efficiency. Thus an optimum tip geometry can be defined as the geometry which has the smallest leakage mass flow rate through the tip gap.

To quantify the losses due to the tip leakage flows, the discharge coefficient $C_{D}$ has been calculated as a loss measure for each tip geometry at different flow conditions. The discharge coefficient is defined as the ratio of the actual mass flow rate, $\dot{m}_{\text {act }}$ to the isentropic mass flow rate, $\dot{m}_{i s e n}$ and expressed by the following equations [36]:

$$
\begin{gathered}
C_{D}=\frac{\dot{m}_{a c t}}{\dot{m}_{\text {isen }}}, \\
\dot{m}_{a c t}=\int_{0}^{h} \rho v_{x} d y,
\end{gathered}
$$

Where $\rho$ and $v_{x}$ are calculated from RANS.

$$
\dot{m}_{\text {isen }}=\sqrt{\frac{\gamma}{R T_{0}}} P_{0} h M\left[1.0+\left(\frac{\gamma-1}{2}\right) M^{2}\right],-(\gamma+1) / 2(\gamma-1) \quad \ldots(2 \mathrm{~b})
$$

Where $M$ is calculated from PR isentropic relationship.

Figure 12 shows the variation of calculated discharge coefficient using RANS data for different flow conditions and pressure ratios PR for both tip geometries. The pressure ratio varies in a range of 0.85 to 0.58 where $P R$ of 0.85 represents a subsonic flow condition and 0.58 represents a transonic condition. 


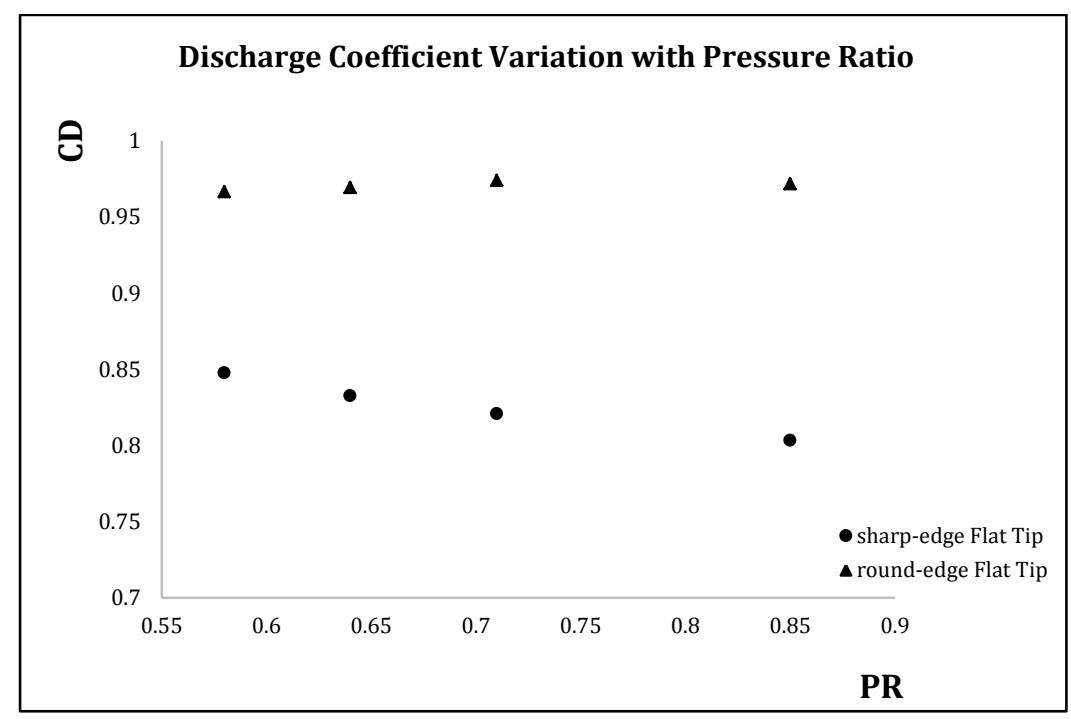

Figure 12: Computational discharge coefficient, $C_{D}$ variation with pressure ratio PR.

The first result that can be clearly captured from this plot is that the discharge coefficient is much larger for the round-edge flat tip in comparison to the sharp-edge model at all tested conditions. As was observed in the experimental Schlieren and RANS contours the round-edge tip removes the separation bubble at the inlet which is present in the case of the sharp-edge tip. Hence the effective tip gap for the flat tip with round edge is larger in comparison to the flat tip with sharp edge. Therefore the tip leakage flow and its associated losses for the round-edge flat tip are expected to be much greater than those in the case of the sharp-edge model as evident in the above plot.

As the pressure ratio PR (i.e. the ratio of the static pressure at the tip gap exit to the stagnation pressure at the inlet to the tip gap) decreases from 0.85 to 0.58 , the static pressure difference across the tip and therefore the acceleration of the tip leakage flow increase and the tip flow changes from subsonic to supersonic. The discharge coefficient increases as the pressure ratio decreases for the sharp-edge geometry. This is because decreasing the pressure ratio increases the acceleration of the tip flows which results into suppression of the separation bubble (which dominates the tip flow for this tip and its size controls the tip leakage flow in this case) at the inlet to the tip gap. Suppression of the separation bubble increases the effective tip gap for this tip geometry and hence increases the tip leakage flows and the associated losses. For the round-edge tip geometry, the discharge coefficient shows a very interesting variation with pressure ratio. As the pressure ratio decreases from 0.85 to 0.58 for this tip, the discharge coefficient first mildly increases and then it decreases. A close look at the values of the PR at which these variations occur, shows that the PR range over which discharge coefficient increases belongs to the tip flows with subsonic and sonic conditions and the PR values over which it decreases corresponds to the tip flows with transonic conditions.

As it was observed earlier the main difference between the two geometries was that in the case of sharp-edge tip, flow separated on its arrival at the tip and produced a large separation bubble at the inlet to the tip gap which dominated the tip flow. The size of the 
separation bubble controlled the tip leakage flow at different PR. Whereas for the roundedge model, the round edge removed this separation at the inlet and the tip flow smoothly adjusted itself around the tip leading edge with no separation. This is a big difference between the two tips and therefore we should expect some difference between the tip flow distributions of the two cases. The work by Ameri and Bunker [29, 30] (which is the only work on the round-edge tip as far as the authors are aware), which was focused on the heat transfer aspect, also showed that the round edge redistributed the flow at the inlet to the tip gap for the round-edge tip in comparison to the sharp-edge tip.

The other important difference between the two geometries was the structure of the shockwaves in both cases. For the sharp-edge tip the oblique shockwave which was formed on the aft portion of the separation bubble reached the casing wall and reflected as another oblique shockwave and the shockwave pattern ended by a normal shockwave. Whereas for the round-edge geometry the acceleration in the traverse direction changed significantly. This was to the extent that at cases with higher pressure difference across the tip, the flow near the tip surface reached Mach number above one and produced a shockwave while the flow close to the casing wall at the same streamwise position remained subsonic. Therefore the shockwave in the case of the round-edge geometry did not reach the casing. As it can be observed there are significant differences between the tip flow developments for both tip geometries particularly at high speed conditions. The absence of the separation bubble and significant acceleration in traverse direction (particularly at high speed conditions), and the structure of the developed shockwave resulted in a different discharge coefficient distribution for the round-edge tip flow with a Mach number above 1 in comparison to the sharp-edge tip.

As discussed above, the discharge coefficient variation for the round-edge model at transonic conditions is opposite to the one for the sharp-edge geometry. This opposite behaviour was explored further via studying and comparing the flow over the round-edge model at two transonic conditions i.e. $P R=0.58$, and $P R=0.64$. Despite the high degree of similarity in the flow pattern, it was found that the flow streamlines for the $P R=0.58$ (i.e. the case with higher flow Mach number) were separated by a larger distance from each other in comparison to the case with PR of 0.64. In other words, the tip leakage flow for pressure ratio of 0.58 were more deflected towards the casing wall than for the pressure ratio of 0.64 where the flow adjusted itself more smoothly around the tip geometry. Greater degree of deflection towards the casing could be due to the structure of the shockwave and hence the acceleration in the traverse direction in the case of this tip geometry. The shockwave became taller for the leakage flow with the higher Mach number. The deflection of the tip flow produced a blockage effect and reduced the tip leakage flows entering the tip gap and their associated losses. Hence it decreased the discharge coefficient. 


\section{CONCLUSION}

This study presents an experimental and computational investigation into leakage flows over high pressure turbine blade tips at high speed conditions. The in-service burnout effect is explored for a flat tip model via testing a sharp-edge flat tip model and a roundedge flat tip model. This is where previous studies mostly looked at the effect of gap height and not the erosion of the tip edge [28]. As far as the authors are aware there is only one work by Ameri and Bunker [29, 30] on the round-edge tip modelling in-service erosion which focused on the heat transfer distribution over the tip and the shroud surfaces of a first stage turbine blade. The work did not include aerodynamic flow measurements other than overall pressure distribution over the tip surface along the pressure side, mean line and suction side of the tip surface. There was no detail on the flow development and behaviour as it crosses the tip from the pressure to the suction side, and there was no flow visualisation to provide more insight into the flow field. Hence our investigation is the first attempt to provide such comprehensive details about the flow development and structure as it crosses the round-edge tip as far as we are aware.

It was found that in the case of the sharp-edge flat tip, flow separated on its arrival at the tip and developed a separation bubble. The separation bubble acted as a vena-contracta and was able to accelerate the tip flow to transonic condition when the pressure difference across the gap was sufficient. The transonic leakage flows included both oblique and normal shockwaves within the tip gap. In addition the effective tip gap for this tip geometry was defined as the minimum distance between the separation bubble and the casing wall and hence was controlled by the size of the separation bubble at the inlet to the tip gap.

However for the round-edge tip model, the round edge removed the separation at the inlet and allowed the flow to adjust itself around the tip smoothly without causing any flow separation. The effective tip gap in this case was equivalent to the geometrical tip gap i.e. the vertical distance between the tip surface and the casing wall. Comparing this tip geometry to the sharp-edge model showed that the effective tip gap in the case of the round-edge tip is much larger than the one for the sharp-edge model. In addition the discharge coefficient $C_{D}$ was greater for the round-edge tip in comparison to the sharpedge geometry at all tested conditions. Hence it was concluded that the in-service burn out effect on the flat tip model removed the separation at the inlet to the tip gap, enlarged the effective tip gap and increased the tip leakage flows and its associated losses.

The discharge coefficient variation with pressure ratio PR showed that in the case of the subsonic tip leakage flows as PR decreased (i.e. as flow Mach number increased) the discharge coefficient increased for both tip geometries. However as the flow category changed to transonic, further decrease in PR (i.e. further increase in flow Mach number) resulted in a further increase in the discharge coefficient for the sharp-edge tip but led to an opposite behaviour for the round-edge model. This was since, at transonic conditions decreasing PR increased the deflection of the flow towards the casing wall for the roundedge tip, which provided some blockage effects and decreased the leakage flow, and hence the discharge coefficient. 
In a following study we will present new results and analysis of models with geometries changes aimed at reducing the leakage flow.

\section{ACKNOWLEDGEMENTS}

The support of the UK Engineering and Physical Sciences Research Council (EPSRC) doctoral training program and Rolls-Royce is greatly acknowledged. The advice given by Dr. Wheeler at University of Cambridge for the experimental set up is also appreciated.

\section{FUNDING STATEMENT}

The support of the UK Engineering and Physical Sciences Research Council (EPSRC) doctoral training program and Rolls-Royce is greatly acknowledged.

\section{REFERENCES}

[1] PARK., J.S. LEE., D.H. RHEE., D.-H. KANG., S.H. CHO., H.H. Heat transfer and film cooling effectiveness on the squealer tip of a turbine blade. Energy 2014; 72: 331343.

[2] REZASOltani., M. LU., K. SCHOBEIRI., M.T. HAN., J.C. A Combined Experimental and Numerical Study of the Turbine Blade Tip Film Cooling Effectiveness under Rotation Condition. ASME Journal of Turbomachinery 2015; 137(5): 051009 051020.

[3] XUE., S. ROY., A. NG., W.F. EKKAD., S.V. A Novel Transient Technique to Determine Recovery Temperature, Heat Transfer Coefficient, and Film Cooling Effectiveness Simultaneously in a Transonic Turbine Cascade. ASME Journal of Therm. Sci. Eng. Appl 2015; 7(1): 011016-011026.

[4] XUE. S., NG., W. F. Turbine Blade Tip External Cooling Technologies. Aerospace Journal, MDPI 2018; 5(3).

[5] GAO, J., ZHENG, Q., ZHANG, H. Comparative investigation of tip leakage flow and its effect on stage performance in shrouded and unshrouded turbines. Proceeding of the Institute of Mechanical Engineering Part G: Journal of Aerospace engineering 2012.

[6] PORRECA. L. KALFAS. A.I. ABHARI. R.S. Optimized Shroud Design for Axial Turbine Aerodynamic Performance. Journal of Turbomachinery 2008; 130: 31016(1-12)

[7] REBHOLZ., P. S. ABHARI., R. S. KALFAS., A. I. ZSCHERP., C. Tip-Shroud cutbacks in a low pressure gas turbine stage. Journal of Propulsion and Power 2016; 32(5): 1077-1086. 
8. CHEN, G., DAWES, W.N., HODSON, H.P. A numerical and experimental investigation of turbine tip gap flow. In: AIAA/SAE/ASME/ASEE 29th Joint propulsion conference and exhibit, Monterey, CA, USA, 28-30 June 1993.

9. DENTON, J.D. Loss mechanisms in turbomachines. Journal of turbomachinery 1993; 115: 621-656.

10. SALEH, Z., AVITAL, E. J., and KORAKIANITIS, T. An investigation into turbine blade tip leakage flows at high speeds. International journal of chemical, Nuclear, Metallurgical and Materials Engineering 2013; 7(1): 9-13.

11. MOORE, J., MOORE, J.G., HENRY, G.S., CHAUDHRY, U. Flow and heat transfer in turbine tip gaps. ASME Journal of Turbomachinery 1988; 111(3): 301-309.

12. MOORE, J, ELWARD, K.M. Shock formation in over expanded tip leakage flow. ASME Journal of Turbomachinery 1993; 115(3): 392-399.

13. HARVEY, N. W. Aerothermal Implications of Shroudless and Shrouded Blades. VKI Lecture Series 2004-02: Turbine Blade Tip Design and Tip Clearance Treatment. Von Karman Institute for Fluid Dynamics, Belgium, 2004.

14. GREEN, B. R., BARTER, J. W., HALDEMAN, C. W., and DUNN, M. G. Averaged and Time-Dependent Aerodynamics of a High Pressure Turbine Blade Tip Cavity and Stationary Shroud: Comparison of Computational and Experimental Results. ASME Journal of Turbomachinery 2005; 127(4): 736-746.

15. MOLTER, S.M., DUNN, M.G., HALDEMAN, C.W., BERGHOLZ, R.F., and VITT, P. Heat-Flux Measurements and Predictions for the Blade Tip Region of a High-Pressure Turbine. In ASME Turbo Expo 2006: Power for land, see, and air, Heat transfer parts A and B, Barcelona, Spain, 8-11 May 2006, paper no. GT2006-90048, pp. 49-60.

16. ZHANG, Q., and HE, L., Over-Tip Choking and its Implications on Turbine Blade Tip Aerodynamic Performance. Journal of Propulsion and Power 2011; 27(5): 10081014.

17. ZHANG, Q., O'DOWD, D. O., HE, L., WHEELER, A. P. S., LIGRANI, P. M., and CHEONG, B. C. Y. Over tip Shock Wave Structure and Its Impact on Turbine Blade Tip HeatTransfer. ASME Journal of Turbomachinery 2011; 133(4): 041001-1-041001-8.

18. AZAD, GM. S., HAN, J.C., BUNKER, R.S., LEE, C.P. Effect of squealer geometry arrangement on a gas turbine blade tip heat transfer. ASME Journal of Heat Transfer 2002; 124(3): 452-459.

19. KEY, N.L. Comparison of turbine tip leakage flow for flat tip and squealer tip geometries at high- speed conditions. Journal of turbomachinery 2006; 128: 213- 220. 
20. PAPA, M., Goldstein, R. J., Gori, F. Effects of tip geometry and tip clearance on the Mass/ Heat transfer from a large-scale gas turbine blade. ASME Journal of Turbomachinery 2003; 125(1): 90-96.

21. SAHA, A.K., ACHARYA, S., BUNKER, R., PRAKASH, C. Blade tip leakage flow and heat transfer with pressure-side Winglet. International journal of rotating machinery 2006; 2006: 1-15.

22. ZHONG, F., ZHOU, C., MA, H., and ZHANG, Q. Heat transfer of winglet tips in a transonic turbine cascade. ASME Journal of Engineering for Gas Turbines and Power 2016; 139(1): 012605 -0126016.

23. AZAD, GM. S. and HAN, J.C. Heat transfer and flow on the squealer tip of a gas turbine blade. Journal of Turbomachinery 2000; 122: 725-732.

24. KWAK, J.S., AHN, J., and HAN, J. C. Effects of rim location, rim height and tip clearance on the tip and near tip region heat of a turbine blade. International journal of heat and mass transfer 2004; 47: 5651-5663.

25. NEWTON, P.J., LOCK, G.D., KRISHNABABU, S.K., HODSON, H.P., DAWES, W.N., HANNIS, J., WHITNEY, C. Heat transfer and aerodynamics of turbine blade tips in a linear cascade. ASME Journal of Turbomachinery, 2006; 128 (2): 300-309.

26. CALONI, S., SHAHPAR, S., COULL, J. D. Numerical investigations of different designs for shroudless turbine blades. Proceedings of the Institution of Mechanical Engineers, Part A: Journal of Power and Energy 2016; 230(7): 709-720.

27. SARAVANAMUTTOO, H., STRAZNICKY, P., COHEN, H., and ROGERS, G. Gas Turbine Theory. England : Prentice Hall, Pearson Education Ltd, 2001.

28. BURNES, D., KURZ, R. Performance degradation effects in modern industrial gas turbines. In Proceedings of Zurich 2018: Global power and Propulsion forum, Zurich, Switzerland, 10-12 January 2018, paper no. GPPS-2018-0019.

29. AMERI, A. A., and BUNKER, R. S. Transfer and Flow on the First-Stage Blade Tip of a Power Generation Gas Turbine: Part 2-Simulation Results. Journal of Turbomachinery 1999; 122(2): 272-277.

30. BUNKER, R. S., BAILY, J. C., AMERI, A. A. Heat Transfer and Flow on the FirstStage Blade Tip of a Power Generation Gas Turbine: Part 1-Experimental Results. Journal of Turbomachinery 1999; 122(2): 263-271.

31. RAINS, D. A., Tip Clearance Flows in Axial Flow Compressors and Pumps, California Institute of Technology, Hydrodynamics and Mechanical Engineering Laboratories. Report. No. 5, 1954. 
32. YARAS, M. I., SJOLANDER, S. A. Effect of simulated rotation on tip leakage in a planar cascade of turbine blades part 1: Tip gap flow. In: ASME, International gas turbine and aero engine congress and exposition. Orlando, FL, 3-6 June 1991, paper no. 91-GT-127.

33. THORPE, S.J., YOSHINO, S., THOMAS, G.A., AINSWORTH, R.W., HARVEY, N.W. Blade- tip heat transfer in a transonic turbine. IMechE Journal of Power and energy 2005; 219(A): 421-430.

34. ATKINS, N. R., THORPE, S. J., AINSWORTH, R. W., Unsteady effects on transonic turbine blade-tip heat transfer. In: ASME Turbo Expo 2008: Power for land, sea and air, Heat transfer parts A and B, Berlin, Germany, 9-13 June 2008, paper no. GT2008-51177, pp 1025- 1038.

35. AMERI, A. Heat Transfer and Flow on the Blade Tip of a Gas Turbine Equipped With a Mean- Camberline Strip. ASME Journal of Turbomachinery 2001; 123(4): 704708 .

36. FORDHAM, G. C. A numerical and experimental investigation of two-dimensional compressible turbine tip gap flow. PhD thesis. Department of Engineering, University of Cambridge, Cambridge, UK, 1994.

37. SETTLES, G. S., Schlieren and shadowgraph techniques: visualising phenomena in transparent media. New York: Springer-Verlag Berlin Heidelberg, 2001.

38. WHEELER, A. P. S and SALEH, Z. Effect of cooling injection on transonic tip flows. Journal of Propulsion and power 2013; 29 (6): 1374-1381. 